\title{
Peran Diet 3J pada Pasien Diabetes Melitus di Puskesmas Sudiang Raya Makassar
}

\author{
Sri Darmawan ${ }^{1 *}$, Sriwahyuni $^{2}$ \\ 1*. STIKES Nani Hasanuddin Makassar, Jl. P. Kemerdekaan VIII No.24, Kota Makassar, Indonesia, 90245 \\ 2. STIKES Nani Hasanuddin Makassar, Jl. P. Kemerdekaan VIII No.24, Kota Makassar, Indonesia, 90245 \\ *e-mail : sridarmawan@stikesnh.ac.id/085342295351
}

(Received : 31-07-2019; Reviewed : 21-08-2019; Accepted : 24-08-2019)

\begin{abstract}
Diabetes mellitus is a clinical syndrome characterized by hyperglycemia caused by a deficiency or decreased effectiveness of insulin. The purpose of this study was to look at the role of diet $3 j$ in patients with diabetes mellitus in the Makassar sudiang raya health center. The research method in this study is to use correlational research with cross sectional design. The population in this study were all patients with diabetes mellitus as many as 90 patients with sampling techniques in this study were accidental sampling, which is a sampling technique based on chance, as many as 48 samples. Data were collected using a questionnaire and data processing using a computer program software SPSS 22 with an error rate $\alpha=(0.05)$ and analyzed using the chi square test with an alternative fisher's exact value $\alpha: 0.05$. The results of data analysis show that there is a role for diet $3 \mathrm{j}$ in patients with diabetes mellitus shown by the value of $p=0.007$ where the patient is able to control the correct food, check blood sugar regularly and take medication regularly. The conclusion in this study $3 \mathrm{~J}$ diet is able to control the increase in blood sugar levels in patients with diabetes mellitus by observing the food and drinks consumed. Suggestions for further researchers need research to further analyze about age, gender, and recent education
\end{abstract}

Keywords : Diet Compliance 3J, DM

\begin{abstract}
Abstrak
Diabetes Melitus merupakan suatu sindrom klinik yang ditandai oleh hiperglikemia yang disebabkan oleh defisiensi atau penurunan efektifitas insulin. Tujuan penelitian ini untuk melihat peran diet $3 \mathrm{j}$ pada pasien diabetes melitus di puskesmas sudiang raya makassar. Metode penelitian dalam penelitian ini adalah menggunakan penelitian korelasional dengan rancangan cross sectional. Populasi dalam penelitian ini adalah semua penderita diabetes melitus sebanyak 90 penderita dengan teknik pengambilan sampel dalam penelitian ini adalah accidental sampling yaitu teknik penentuan sampel berdasarkan kebetulan, sebanyak 48 sampel. Data dikumpulkan dengan menggunakan kuesioner-dan pengolahan data menggunakan program komputer software SPSS 22 dengan tingkat kesalahan $\alpha=(0,05)$ dan dianalisis menggunakan uji chi square dengan nilai alternative fisher's exact $\alpha: 0,05$. Hasil analisa data menunjukkan bahwa ada peran diet $3 \mathrm{j}$ pada pasien diabetes mellitus ditunjukkan dengan nilai $p=0,007$ dimana pasien mampu mengonrol makanan yang benar, memerisakan gula darah secara rutin dan minum obat secara teratur. Kesimpulan dalam penelitian ini diet $3 \mathrm{~J}$ mampu mengontrol peningkatan kadar gula darah pada pasien diabetes melitus dengan cara patuh atau memperhatikan makanan dan minuman yang dikomsumsi. Saran bagi peneliti selanjutnya perlu adanya penelitian untuk menganalisis lebih jauh tentang usia, jenis kelamin, dan pendidikan terakhir
\end{abstract}

Kata Kunci : Diet 3J, DM, Kepatuhan 


\section{Pendahuluan}

Penyakit diabetes melitus semakin banyak diderita penduduk dunia. Jumlah penderita diabetes melitus bertambah karena usia harapan hidup (UHH) semakin meningkat, terutama di negara-negara maju sehingga berdampak pada jumlah penderita diabetes melitus di dunia. Banyak penderita diabetes melitus yang bertahan sampai lanjut usia meskipun sampai sekarang belum ada obat yang bisa menyembuhkan penyakit ini (Marewa, 2015).

Gangguan penyembuhan luka pada diabetes dapat dikaitkan dengan beberapa faktor termasuk suplai darah yang tidak memadai, penurunan potensi proliferasi fibroblas, dan penurunan perubahan inflamasi.(ApikogluRabus, Izzettin, Turan, \& Ercan, 2010). Penyakit diabetes melitus yang ditandai dengan terjadinya peningkatan kadar glukosa dalam darah jika terjadi secara terus menerus dapat berpengaruh buruk bagi tubuh kita dan akan menyebabkan terjadinya komplikasi sehingga dibutuhkan terapi untuk menurunkan kemungkinan terjadinya komplikasi. Salah satu faktor untuk mencegah terjadinya komplikasi adalah patuh dalam menjalankan diet (Risti \& Isnaeni, 2017).

Pasien diabetes perlu diberikan beberapa perawatan agar tidak semakin parah dan tidak mengalami komplikasi yang dapat menimbulkan masalah kesehatan baik makroangiopati maupun mikroangiopati (Adi Sucipto1,) melakukan diet yang merupakan pengaturan pola makan yang tepat ditentukan dari 3J yaitu jadwal makan, jumlah makan, dan jenis makan. Dalam menjalankan terapi tersebut penderita diabetes melitus harus memiliki sikap yang positif Apabila penderita diabetes melitus memiliki sikap yang positif, maka dapat mendukung terhadap kepatuhan diet diabetes melitus itu sendiri. Selain itu jika terjadi luka kronik pada penderita Diabetes Mellitus maka dibutuhkan Oksigen yang cukup untuk penyembuhan luka melalui proses reparatif seperti proliferasi sel, pertahanan bakteri, angiogenesis dan sintesis kolagen(Schreml et al., 2010)

Salah satu faktor utama kegagalan sebuah terapi adalah ketidakpatuhan terhadap terapi yang telah direncanakan, maka salah satu upaya penting untuk meningkatkan kepatuhan pasien terhadap terapi adalah dengan edukasi atau pemberian konseling yang lengkap, akurat serta secara terstruktur tentang terapi tersebut(Vatankhah, Ebrahim, \& Jahangiri, 2009). Menurut Word Health Organisation, 2016 dikutip dalam Hestiana (2017) Jumlah penderita diabetes melitus didunia sebanyak 422 juta jiwa. Pada tahun 2015, prevelensi angka kejadian diabetes melitus didunia adalah mencapai 415 juta penderita. Indonesia masuk urutan ke tujuh dunia pada tahun 2015 dengan jumlah 10 juta penderita. Jumlah penyandang Diabetes di Indonesia mencapai angka 425 juta orang pada tahun 2017(Hestiana, 2017)

Menurut International Diabetes Federation, 2017 dikutip dalam Raudatul,H (2018) Proyeksi tersebut diprediksi meningkat mencapai 16,7 juta orang pada tahun 2045. Hasil Riset Kesehatan Dasar (riskesdas) pada tahun 2016 menunjukkan bahwa angka diabetes melitus meningkat 6,9\% dari hasil riset sebelumnya dari tahun 2013 (Ningsih, Bayhakki, \& Woferst, 2018). Kasus DM di Sulawesi-Selatan yang disebut prevalensi kencing manis berkisar antara $1 \%-6,1 \%$, yang terbesar di 25 kabupaten/kota. Kasus kencing manis paling banyak terdapat di kabupaten/kota tanah toraja $(6,1 \%)$, makassar $(5,3 \%)$, dan luwu $(5,2 \%)$, kasus terendah adalah di kabupaten/kota pangkajene kepulauan, enrekang, dan luwu timur masing-masing 1\% (Marewa, 2015). Berdasarkan Data Puskesmas Sudiang Raya Kota Makassar, menunjukkan bahwa jumlah penderita Diabetes Melitus pada tahun 2016 sebanyak 428 orang, dan mengalami peningkatan pada tahun 2017 menjadi 597 orang, dengan menduduki peringkat ke-2 di Puskesmas. Sedangkan jumlah penderita pada tahun 2018 mulai bulan Januari - Februari yaitu 90 orang (Raudatul Hasanah, 2018)

\section{Metode}

Desain penelitian yang digunakan pada penelitian ini adalah penelitian korelasional dengan rancangan cross sectional. Lokasi Penelitian ini dilaksanakan di Puskesmas Sudiang Raya Makassar pada tanggal 16 juli sampai 28 juli 2018. Populasi dalam penelitian ini adalah semua pasien diabetes melitus yang berobat di Puskesmas Sudiang Raya Makassar, dilihat dari jumlah dua bulan terakhir pada tahun 2018 mulai dari bulan Januari sampai Februari sebanyak 90 populasi. Sampel dalam penelitian ini terdapat 48 responden yang memenuhi Kriteria inklusi dan eklusi yaitu pasien dengan komlikasi Diabetes Mellitus. Data dan informasi yang diperoleh dengan menggunakan alat ukur Angket/ koesioner.

\section{Hasil Penelitian}

1. Analisis Univariat

Analisis univariat bertujuan untuk menjelaskan atau mendeskripsikan karakteristik setiap variabel penelitian pada umumnya nalisi ini menghasilkan distribusi frekunsi dan presentase dari tiap variabel, analisi univariat dalam penelitian ini meliputi Jenis Kelamin, Usia, Pendidikan dan tipe Diabetes Mellitus 
a. Jenis Kelamin

Tabel 1. Distribusi Responden Berdasarkan Jenis Kelamin Penderita Penyakit Diabetes Melitus Di Puskesmas Sudiang Raya Makassar

\begin{tabular}{ccc}
\hline Jenis Kelamin & Frekuensi & Persentase (\%) \\
\hline Laki- Laki & 22 & 45,8 \\
Perempuan & 26 & 54,2 \\
\hline Total & 48 & $100 \%$ \\
\hline
\end{tabular}

Berdasarkan tabel 1. Menunjukkan bahwa dari 48 responden yang berjenis kelamin perempuan sebanyak 26 responden $(54,2)$ dan jenis kelamin laki-laki sebanyak 22 responden $(45,8)$.

b. Usia

Tabel 2. Distribusi Responden Berdasarkan Usia Penderita Penyakit Diabetes Melitus Di Puskesmas Sudiang Raya Makassar

\begin{tabular}{ccc}
\hline Usia & Frekuensi & Persentase (\%) \\
\hline 40-50 tahun & 17 & 35,4 \\
$51-60$ tahun & 27 & 56,2 \\
$61-70$ tahun & 4 & 8,3 \\
\hline Total & 48 & $100 \%$ \\
\hline
\end{tabular}

Berdasarkan tabel 2. Menunjukkan bahwa dari 48 responden sebagian besar berusia 51-60 tahun sebanyak 27 responden $(56,2)$, usia 40-50 tahun sebanyak 17 responden $(35,4)$ dan usia 61-70 tahun sebanyak 4 responden $(8,3)$

c. Pendidikan

Tabel 3. Distribusi Responden Berdasarkan Pendidikan Penderita Penyakit Diabetes Melitus Di Puskesmas Sudiang Raya Makassar

\begin{tabular}{ccc}
\hline Pendidikan & Frekuensi & Persentase (\%) \\
\hline SD & 7 & 14,6 \\
SMP & 17 & 35,4 \\
SMA & 15 & 31,2 \\
SARJANA & 9 & 18,8 \\
\hline Total & 48 & $100 \%$ \\
\hline
\end{tabular}

Berdasarkan tabel 3. Menunjukkan bahwa dari 48 responden menurut tingkat pendidikan sebagian besar responden pendidikan SMP sebanyak 17 responden $(35,4)$, SMA sebanyak 15 responden $(31,2)$, SMA 9 responden $(18,8)$ dan terendah SD Sebanyak 7 responden $(17,6)$.

d. Tipe Diabetes Mellitus

Tabel 4. Distribusi Responden Berdasarkan Tipe Diabetes Mellitus Penderita penyakit Diabetes Melitus di Puskesmas Sudiang Raya Makassar

\begin{tabular}{ccc}
\hline Jenis Kelamin & Frekuensi & Persentase (\%) \\
\hline DM Type I & 27 & 64,6 \\
DM Type II & 21 & 35,4 \\
\hline Total & 48 & 100,0 \\
\hline
\end{tabular}

Berdasarkan tabel 4. Menunjukkan bahwa dari 48 responden yang mengalami DM type I sebanyak 27 responden $(64,6)$ dan mengalami DM type II sebanyak 21 responden $(35,4)$.

2. Analisi Bivariat

Analisi bivariat yang dilakukan terhadap dua variabel yang diduga berhubungan atau berkolerasi. Analisi bivariat dalam penelitian ini bertujuan untuk melihat hubungan distribusi antara variabel independent dan variabel dependent. 
Hubungan Antara Kepatuhan dengan Diet 3J

Tabel 2. Hubungan Kepatuhan dengan Diet 3J pada Pasien Diabetes Melitus di Puskesmas Sudiang Raya Makassar

\begin{tabular}{|c|c|c|c|c|c|c|}
\hline \multirow{3}{*}{ Diet 3J } & \multicolumn{4}{|c|}{ Diabetes Melitus } & \multirow{2}{*}{\multicolumn{2}{|c|}{ Total }} \\
\hline & \multicolumn{2}{|c|}{ Tipe I } & \multicolumn{2}{|c|}{ Tipe II } & & \\
\hline & $\mathrm{n}$ & $\%$ & $\mathrm{n}$ & $\%$ & $\mathrm{n}$ & $\%$ \\
\hline Patuh & 22 & 45,8 & 9 & 18,8 & 31 & 64,6 \\
\hline Tidak patuh & 5 & 10,4 & 12 & 25,0 & 17 & 35,4 \\
\hline \multicolumn{7}{|c|}{$\rho=0,007 \quad \alpha=0,05$} \\
\hline
\end{tabular}

Dari 48 responden $(100 \%)$, responden yang patuh menjalani menjalankan diet $3 \mathrm{~J}$ sebanyak 31 responden $(64,6 \%)$ dan yang menderita DM tipe I sebanyak 22 responden $(45,8 \%)$ dan DM tipe II sebanyak 9 responden $(18,8 \%)$, sedangkan responden yang tidak patuh menjalankan diet $3 \mathrm{~J}$ sebanyak 17 responden $(35,4 \%)$ dan yang menderita DM tipe I sebanyak 5 responden $(10,4 \%)$ dan DM tipe II sebanyak 12 responden $(25,0 \%)$. Berdasarkan hasil uji statistic memperlihatkan nilai $p=0,007$ dan ketentuan signifikan $p$ $<0,05$ maka 0,007 < 0,05, berarti Ha diterima Ho di tolak sehingga terdapat ada hubungan Kepatuhan Diet 3J pada Pasien Diabetes Melitus di Puskesmas Sudiang Raya Makassar

\section{Pembahasan}

Berdasarkan distribusi karakteristik responden kepatuhan diet $3 \mathrm{j}$ terdapat responden yang patuh berjumlah 31 responden dimana dari hasil penelitian mereka dapat menghindari makanan atau minuman yang manis-manis yang dikonsumsi setiap hari, memperbanyak mengonsumsi buah dan sayuran. Sedangkan yang tidak patuh berjumlah 17 responden, dari hasil penelitian yang dilakukan responden mengatakan masih sering mengonsumsi makanan yang siap saji, mengonsumsi makanan atau minuman yang manis-manis, dan responden belum mampu untuk mengikuti jadwal makan yang sehat.

Berdasarkan hasil penelitian yang dilakukan oleh Nur Sam 2017 tentang analisa hubungan Activity Of Daily Living $(A D L)$, aktivitas fisik dan kepatuhan diet terhadap kadar gula darah pasien diabetes melitus mengatakan bahwa kepatuhan diet adalah suatu perilaku pasien dalam melaksanakan pemenuhan asupan makanan yang telah direkomendasikan oleh penyedia pelayanan kesehatan. Pelaksanaan diet pada pasien diabetes melitus ada empat pilar yang perlu diperhatikan, yaitu : edukasi, perencanaan makan, pelatihan jasmani, dan intevensi abologis. Interaksi diet mempengaruhi pola lemak tubuh yang memiliki peranan yang sangat signifikan dalam menentukan sensitivitas insulin. Modifikasi diet dapat dilakukan dengan menghindari asupan kalori yang berlebihan dan diet tinggi lemak dengan mengonsumsi karbohidrat kompleks, buah, dan sayur-sayuran.(Ulfah \& Rahayuni, 2018). Menurut Bandura, sumber pengontrol tingkah laku adalah resiprokal antara lingkungan, tingkah laku, dan pribadi. Efikasi diri namun setiap individu mempunyai efikasi diri (Self Efficacy) yang berbeda-beda pada situasi yang berbeda, tergantung kepada Kepatuhan penderita dalam menjalankan diet diabetes melitus akan memiliki kontrol gula darah yang lebih baik, dengan adanya kontrol gula darah yang baik dapat mencegah terjadinya komplikasi. Kepatuhan untuk menjalankan diet akan terasa sulit dilakukan jika kurangnya pemahaman tentang kepatuhan diet seperti apa yang harus dilakukan untuk mengontrol gula darah penderita, kemudian rendahnya dukungan keluarga penderita diabetes sehingga berdampak negatif bagi penderita diabetes itu sendiri.(Ley et al., 2016)

\section{Kesimpulan}

Kesimpulan dalam penelitian ini Diet 3J mampu mengontrol peningkatan kadar gula darah pada pasien diabetes melitus dengan cara memperhatikan makanan dan minuman yang dikomsumsi. Berdasarkan distribusi karakteristik responden kepatuhan diet $3 \mathrm{j}$ terdapat responden yang patuh berjumlah 27 responden dimana dari hasil penelitian mereka dapat menghindari makanan atau minuman yang manis-manis yang dikonsumsi setiap hari, memperbanyak mengonsumsi buah dan sayuran. Sedangkan yang tidak patuh berjumlah 21 responden, dari hasil penelitian yang dilakukan responden mengatakan masih sering mengonsumsi makanan yang siap saji, mengonsumsi makanan atau minuman yang manis-manis, dan responden belum mampu untuk mengikuti jadwal makan yang sehat

\section{Saran}

Bagi penderita diabetes melitus agar melakukan penatalaksanaan dengan tepat dan benar serta teratur berobat. Bagi pihak institusi Puskesmas, diharapkan lebih memperhatikan penatalaksanaan pada penderita diabetes melitus dimana sangat berperan dalam proses perawatan diabetes melitus khususnya diet diabetes 
melitus. Bagi peneliti keperawatan selanjutnya hasil penelitian ini dapat dijadikan sebagai data awal atau sumber referensi, kemudian perlu adanya penelitian untuk menganalisis lebih jauh tentang usia, jenis kelamin, dan pendidikan terakhir.

\section{Referensi}

Adi Sucipto1, E. M. R. (n.d.). Efektivitas Konseling DM dalam Meningkatkan Kepatuhan dan Pengendalian Gula Darah pada Diabetes Melitus Tipe 2, 9-20.

Apikoglu-Rabus, S., Izzettin, F. V., Turan, P., \& Ercan, F. (2010). Effect of topical insulin on cutaneous wound healing in rats with or without acute diabetes. Clinical and Experimental Dermatology, 35(2), 180-185. https://doi.org/10.1111/j.1365-2230.2009.03419.x

Hestiana, D. W. (2017). FAKTOR-FAKTOR YANG BERHUBUNGAN DENGAN KEPATUHAN DALAM PENGELOLAAN DIET PADA PASIEN RAWAT JALAN DIABETES MELLITUS TIPE 2 DI KOTA SEMARANG. Jurnal of Health Education, 2(2), 138-145.

Ley, S. H., Pan, A., Li, Y., Manson, J. A. E., Willett, W. C., Sun, Q., \& Hu, F. B. (2016). Changes in overall diet quality and subsequent type 2 diabetes risk: Three U.S. prospective cohorts. Diabetes Care (Vol. 39). https://doi.org/10.2337/dc16-0574

Marewa, L. W. (2015). Kencing Manis (Diabetes Melitus) di Sulawesi Selatan (Pertama). Jakarta: Yayasan Pustaka Obor Indonesia.

Ningsih, H. R., Bayhakki, \& Woferst, R. (2018). Hubungan Self Efficacy Terhadap Kepatuhan Diet Pada Penderita DM, 212-219.

Raudatul Hasanah, D. C. A. (2018). Hubungan antara status gizi dengan kadar gula darah pada penderita diabetes mellitus tipe ii di puskesmas gamping i.

Risti, K. N., \& Isnaeni, F. N. (2017). Hubungan Motivasi Diri Dan Pengetahuan Gizi Terhadap Kepatuhan Diet DM Pada Pasien Diabetes Melitus Tipe II Rawat Jalan Di RSUD Karanganyar. Jurnal Kesehatan, 10(2), 94-103.

Schreml, S., Szeimies, R. M., Prantl, L., Karrer, S., Landthaler, M., \& Babilas, P. (2010). Oxygen in acute and chronic wound healing. British Journal of Dermatology, 163(2), 257-268. https://doi.org/10.1111/j.13652133.2010.09804.x

Ulfah, M., \& Rahayuni, A. (2018). Efek Konseling Gizi terhadap Pengetahuan dan Kepatuhan Pembatasan Intake Cairan pada Pasien Chronic Kidney Disease ( CKD ) di RSUD Abdul Wahab Sjahranie Samarinda, 20(1), 27-33. https://doi.org/10.29238/jnutri.v20i1.253

Vatankhah, N., Ebrahim, M., \& Jahangiri, Y. (2009). The effectiveness of foot care education on people with type 2 diabetes in Tehran, Iran, 3, 73-77. https://doi.org/10.1016/j.pcd.2009.05.003 